\title{
Recontextualising NAPLAN: A functional analysis of evaluations in media texts
}

\author{
Lungguh Ariang Bangga ${ }^{*}$ and Iwa Lukmana ${ }^{2}$ \\ ${ }^{1}$ Department of Linguistics, Faculty of Arts and Social Sciences, The University of Sydney, John Woolley Building A20, \\ Science Road, The University of Sydney, NSW 2006, Australia \\ ${ }^{2}$ Department of English Education, Faculty of Language and Literature Education, Universitas Pendidikan Indonesia, \\ Jl. Dr. Setiabudhi No. 229 Bandung, West Java, Indonesia
}

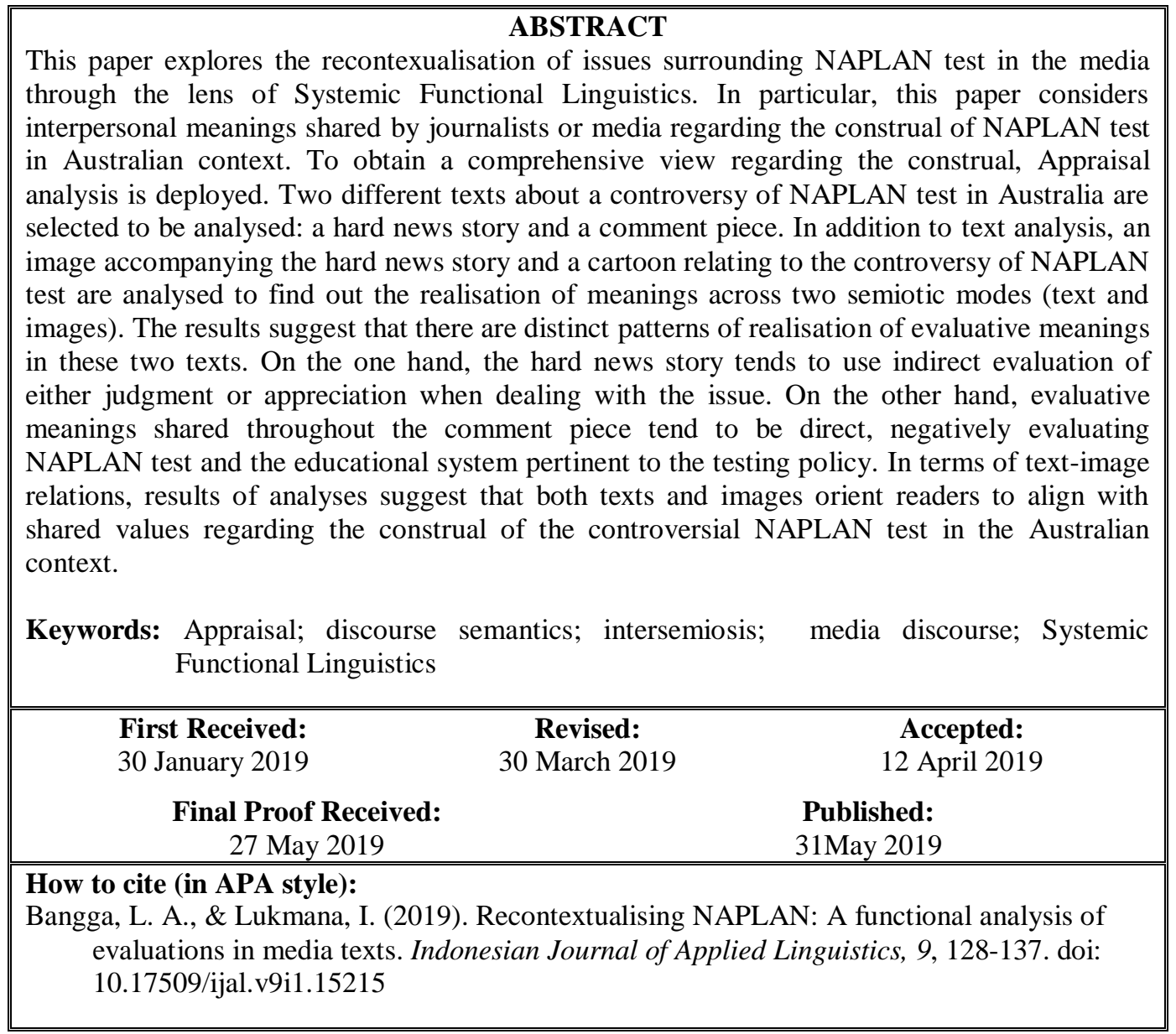

\section{INTRODUCTION}

The Australian National Assessment Program - Literacy and Numeracy (NAPLAN) is an annual census testing given to students in Year 3, 5, 7, and 9 throughout Australia (ACARA, 2017). The primary aim of this test is to measure improvements of students' learning outcomes and to provide an accountable progress report for the communities regarding education quality. In doing so, the Australian Federal Government sets up the basis of students' learning outcomes in primary and secondary schools with regard to four basic abilities, i.e.
Reading, Writing, Language Convention (spelling, grammar, and punctuation), and Numeracy.

Upon its enactment in Australian education contexts, NAPLAN retains its status as a high-stakes test. Result of NAPLAN test then becomes a primary means for judging students' performance and driving school improvements (Angelo, 2013). It becomes a single favoured source of data in deciding students' success or failure in meeting education standards in Australia. However, as NAPLAN is used as a single source of data, it may not 'objectively' measure the

\footnotetext{
* Corresponding Author

Email: lban4926@uni.sydney.edu.au
} 
actual achievement of students in primary and secondary levels of education (Johnston, 2017).

There are some other problems regarding NAPLAN test, seen from its backwash towards teaching practices, psychological impacts for both teachers and students, and its representation in the public sphere. As NAPLAN outcome is considered a proxy of teachers' quality (Cumming, Wyatt-Smith, \& Colbert, 2016), teachers are seen as the most responsible party for any success or failure regarding students' performance. This, then, drives the shift on pedagogical practices carried out by teachers at schools - a shift from the teaching of content to the teaching to face the test (Thompson \& Harbaugh, 2013). In relation to both teachers' and students' psychological dimensions, NAPLAN is clearly problematic. For students, NAPLAN is a heavy burden, leading to an uncomfortable feeling as their learning over years will be judged solely based on the results of their NAPLAN test (Johnston, 2017). For teachers, preparing students to only face this test will result in a negative consequence to classroom environment and students' engagement (Thompson \& Harbaugh, 2013). Similarly, NAPLAN should also be carefully monitored as it potentially disadvantages indigenous students or those coming from minority communities in Australia (Wigglesworth, Simpson, \& Loakes, 2011).

In the public sphere, debates surrounding the implementation and drawbacks of NAPLAN have been familiar in many printed or electronic media in Australia annually (Lingard, Thompson, \& Sellar, 2016). According to Mockler (2013), the coverage of NAPLAN in news reporting increases both quantitatively and qualitatively in the first three years of its implementation in Australian education, following a seemingly consistent pattern to the current situation. Further, a study by Mockler (2016) points out that the coverage of NAPLAN in printed media is centralised around problems such as fear of poor achievement, fear of test, and fear of unfamiliar teaching strategies, thus positioning readers to perceive NAPLAN as something that is undoubtedly problematic and needs careful attention.

However, as NAPLAN is perceived as being problematic, be it from scholarly or public standpoint, there is a need to make explicit how the construal of such a problematic testing is done. This paper attempts to explore how media texts recontextualise the construal through the lens of Systemic Functional Linguistics. This paper focuses on the investigation of interpersonal meanings registered through texts by deploying an Appraisal analysis (Martin \& Rose, 2007; Martin \& White, 2005), especially ATTITUDE and ENGAGEMENT, to unpack how journalists/media put evaluations towards NAPLAN. In addition, a specific reference to the analysis of images (photojournalism and cartoon) accompanying the reporting on NAPLAN is also addressed to find out the interrelations of meanings construed through two modes of communications. It must be noted that this paper, rather than analysing a large corpus of media reporting on NAPLAN, focuses on a small corpus of texts published online in a prominent newspaper in Australia, Sydney Morning Herald. Regarding this, it must also be emphasised that the texts are not the primary point of interest; rather this paper delineates methodological approaches to investigate evaluative resources in media texts which are also appliable to texts of any kind. Thus, this paper is geared towards exemplifying the appliability of Appraisal theory in order to understand how texts, as well as imagic resources, position audiences and negotiate solidarity regarding the issue surrounding NAPLAN test.

\section{An overview of Systemic Functional Linguistics}

This paper is given shape by Systemic Functional Linguistics (hereafter SFL) approach to discourse analysis. SFL concerns language as a meaning making resource rather than a set of formal grammatical rules governing language structure (Halliday, 1978; Halliday \& Matthiessen, 2014; Martin, 1992). In this perspective, language is seen semiotically as construing meanings influenced by social functions it serves to address. In so doing, SFL enacts several theoretical dimensions of language relating to the construal of meaning within a particular social context. These dimensions are called stratification, rank scale, metafunctions, and axis. For the purpose of this paper, only stratification and metafunctions will be reviewed briefly here (see Halliday \& Matthiessen, 2014; Martin, 1992, 2013; Matthiessen \& Halliday, 2009 for further details on theoretical dimensions in SFL).

Stratification has to do with the assumption that language is organised into a stratified system, organising it into a cline of abstraction (Halliday \& Matthiessen, 1999). In order to realise meanings in context, following Martin (1992), language is stratified into five levels of abstraction, i.e. phonology/morphology, lexicogrammar, discourse semantics, register, and genre. Phonology/graphology deals with the patterns of speech and writing which constitute the expression plane of language (Halliday \& Matthiessen, 1999; see also Hjelmslev, 1961). Lexicogrammar has to do with the construal of meanings in clause level. Discourse semantics focuses on the organisation of meanings in text level (Martin, 1992; Martin \& Rose, 2008), which will become the point of departure of analysis in relation to the purpose of this paper. Register and genre contribute to the establishment of context, which plays a central role in coordinating choices of language in lower strata, i.e. discourse semantics, lexicogrammar, and phonology. In other words, language and context are intimately relating to one another in that choices in each stratum of language will contribute to the realisation of meanings in register variables and genres (Martin, Quiroz, \& Wang, in preparation).

Metafunctions have to do with the functions that language serves in relation to the social contexts organising its use. There are three broad functions that 
language serves in a communicative event, i.e. ideational, interpersonal, and textual metafunctions (Eggins, 2004; Eggins \& Slade, 1997; Halliday \& Matthiessen, 2014; Martin \& Rose, 2008). Ideational metafunction construes experiences, either in our external world or in our inner consciousness. Ideational metafunction relates to register variable of field with respect to the configuration of activities orienting to some global purposes (Martin, 1992). Interpersonal metafunction enacts social relationships, as well as evaluations shared between interlocutors, through the use of language. It is internally linked with register variable of tenor. Textual metafunction enables text to weave together the ideational and interpersonal meanings into a discursive event. These metafunctions are simultaneously construed in a single instance of language use. The relations between metafunctions and stratification of language can be seen in Figure 1, representing functional diversifications of language and their relations to contextual features.

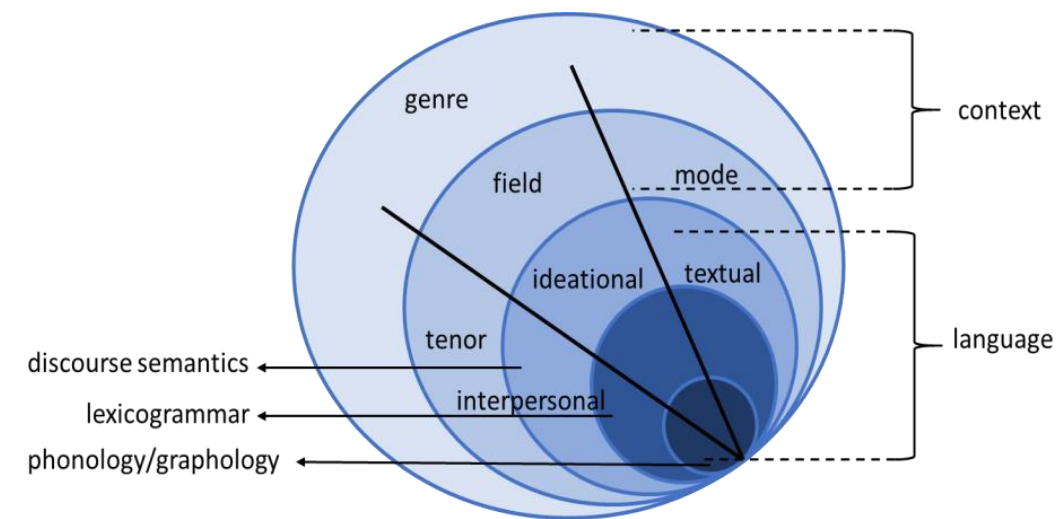

Figure 1 Functional diversification of language in relation to contextual features (adapted from Martin \& Rose, 2008)

As our focal point of analysis concerns evaluations in media texts, this paper will turn its attention to the interpersonal domain of meanings, i.e. Appraisal analysis in discourse semantics and its relation to realising meanings in register variable, tenor.

\section{Appraisal framework}

Appraisal is one major discourse semantics resource for construing interpersonal meanings, especially with regard to the enactment of feelings, assessment towards people's behaviour, and evaluations towards things or phenomena (Martin \& White, 2005). In other words, Appraisal concerns the negotiation of social relationships between writers/speakers with their potential audiences. There are three major systems in Appraisal: ATTITUDE, ENGAGEMENT, and GRADUATION.

ATTITUDE refers to ways people evaluate people, things, and their surroundings. ATTITUDE is further diversified into three subcategories with regard to the kind of evaluation shared in a text: affect, judgement, and appreciation. According to Martin and Rose (2007), affect construes our feelings in relation to the domain of sadness/happiness, satisfaction/dissatisfaction, security/insecurity, and so on. Judgment deals with the evaluation towards people's characters and/or their behaviour with regard to their personal evaluations, as well as moral evaluations such as praise or condemnation. Appreciation refers to the evaluations of things or phenomena. In this category, the evaluations are distinguished into three regions, i.e. reactions, compositions, and values. As far as attitudinal resources are concerned, our evaluations or feelings can be upscaled or downscaled - we can adjust our evaluations about someone or something. The adjustment of evaluations is referred to as GRADUATION.

ENGAGEMENT concerns the sourcing of evaluations in the discourse. Adopting Bakhtinian perspective of dialogic engagement in the discourse, the system of ENGAGEMENT differentiates two major categories of sourcing evaluations, i.e. monoglossic and heteroglossic (White, 2004). In other words, this system has to do with the linguistic resources used for adopting stances towards the value positions in the texts (Martin $\&$ White, 2005). In relation to the purpose of this paper, this resource is crucial in unveiling how media texts position information with respect to the potential audiences they intend to share the information with. This resource also makes a contact with what Feez, Iedema, and White (2008) call authorial voices. Furthermore, as a consequence of a value positioning in the discourse, speaker/writer can indicate their stance with respect to other members of their communities, by either aligning or disaligning with the communal values held in those particular discourse communities (White, 2008). With respect to authorial voices, the sourcing of evaluations can help decide whether texts are soundingly 'objective' or 'subjective' - attributing evaluations to other sources or positioning evaluations solely based on speaker/writer's experiences.

As far as evaluations shared in the discourse are concerned, there are at least four things that should be taken into account when carrying out an Appraisal analysis: Appraiser, Appraising Items, Appraised, and types of evaluations. According to Martin and White (2005), Appraiser refers to the source of evaluations who evaluates what in which circumstances; Appraising Items are the lexical items that contain evaluations, such 
as adjectives, verbs, or nominal groups; Appraised has to do with the target of evaluations, be it people or things; and type of evaluations refer to the degree of explicitness of evaluations - it can be explicit (inscribed) or implicit (invoked). In terms of implicit evaluations, there is an absence of attitudinal lexis. The evaluations, indeed, are infused to the selection of ideational meanings that are used to invite potential audiences to feel or to share evaluations. The outline of Appraisal framework is provided in Figure 2.

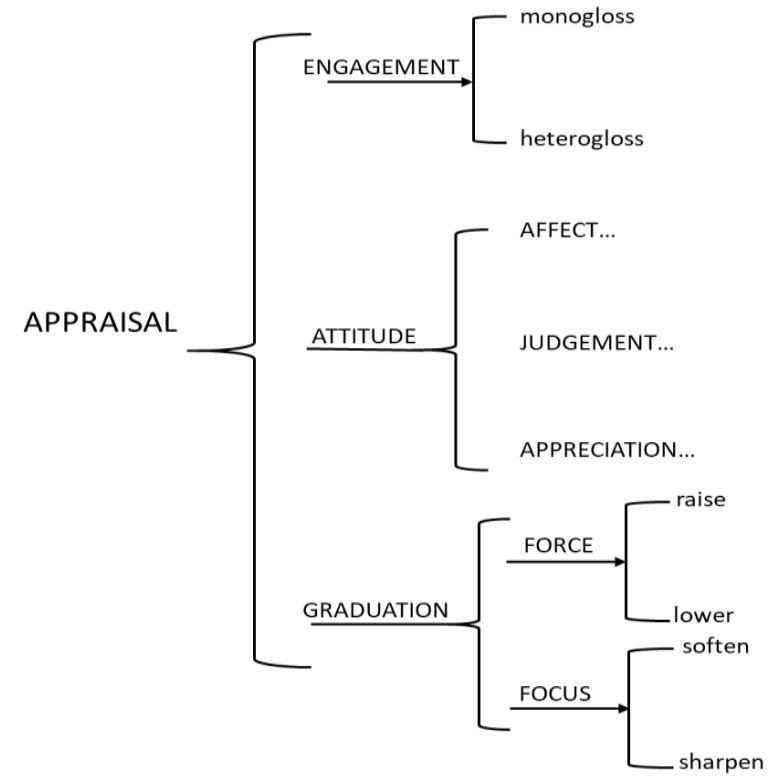

Figure 2 An overview of Appraisal system networks (Martin \& White, 2005)

\section{Framework for analysing imagic resources}

As previously mentioned, in addition to unpacking interpersonal meanings of texts utilising Appraisal analysis, this paper also includes an analysis of an image and a cartoon relating to the issue of NAPLAN test in Australia. For this purpose, this paper relies on Kress and van Leeuwen's (2006) grammar of visual designs, especially image orientation and ambience, for analysing interpersonal meanings construed by imagic resources. As far as interpersonal meanings in the image are concerned, two primary systems can be proposed to see how images negotiate feelings and position audiences: image orientation and ambience. The first system is image orientation. The image orientation system refers to the way image-makers construe an imaginary relationship between viewers and images. There are several choices that can be observed when dealing with orientational meanings: contact, affect, involvement, power, and social distance. These resources primarily deal with certain elements that can suggest particular relationships between viewers and images, such as types of shot, angles, eye contacts, and facial expressions.

The second system is ambience - the role of colour. Kress and van Leeuwen (2002) provide a distinctive way of analysing colours in relation to the construal of emotions or feelings in the image. They distinguish three broad systems regarding the contribution of colours to the interpersonal domain of meanings: vibrancy, warmth, and familiarity. With respect to the purpose of this paper, these systems can be applied in justifying the interpretation regarding interpersonal meanings that are construed in the image accompanying the hard news story and the cartoon relating to the issue of NAPLAN test. The complementarity between linguistic and imagic resources will establish a nuanced analysis regarding interpersonal meanings construed in two different semiotic modes. As a result, these analyses will be beneficial in establishing how texts and images position their potential audiences/viewers to align with particular values regarding the issue of NAPLAN test.

\section{METHOD}

A qualitative discourse analysis utilising SFL toolkits is used to investigate the recontextualisation of NAPLAN in media texts. Specifically, an Appraisal analysis of a hard news story and a comment piece is deployed to find out how journalists/media shared their interpersonal meanings throughout the texts. The texts that are analysed in detail are taken from an online newspaper Sydney Morning Heralds, a major metropolitan and national newspaper under Fairfax Media (Mockler, 2016). The hard news story High expectations, attendance key to lifting NAPLAN scores: report, was written by Alexandra Smith and was published on 4 September 2017. The comment piece How many of our bosses would have aced NAPLAN test? was written by Madonna King and was published a month earlier than the hard news story. These two texts view the NAPLAN test from different angles. On the one hand, the hard news story elaborates potential factors that may contribute to students' achievement on NAPLAN test. On the other hand, the comment piece challenges a view regarding putting blame on teachers in relation to the 
outcome of NAPLAN test. In addition to these texts, this paper attempts to analyse an accompanying image and a political cartoon relating to the issue of NAPLAN test. This attempt seeks to see the contribution of linguistic and imagic resources to the overall organisation of meanings and evaluations of the issue presented in two different semiotic modes.

\section{FINDINGS AND DISCUSSIONS}

This section presents and discusses findings regarding how media texts recontextualise the construal of NAPLAN. This section is divided into five subsections, comprising the evaluation patterns in hard news story, the evaluation patterns in comment piece, interpersonal meanings in photojournalism, interpersonal meanings in political cartoon, and text-image relations.

\section{Evaluations in hard news story}

The evaluations in hard news story tend to be indirect in a sense that when evaluating people or phenomena, the text attributes the evaluations to other reliable sources. In this case, the source of evaluations is primarily $a$ report that shares some potential factors to lift students' NAPLAN outcome. That is to say, the use of attribution of information characterises the hard news story as having a reporter voice in that the information delivered will be perceived by the readers as something 'objective'. In so doing, the voice is constructed as impersonal by sharing the knowledge of material events that occur in the real worlds through the attribution of other voices (Feez et al., 2008). In other words, the 'objectivity' about the information reported in the hard news story is not revolving around the feelings or thought that people might have regarding problems on NAPLAN; rather the information is oriented towards results of a study which delineates some factors that are potential in lifting NAPLAN outcome such as high expectations, positive behaviour, and academic motivation. In relation to the attributed source, the hard news story can be said to acknowledge the information from the source with the purpose of presenting the attributed proposition for readers' considerations (White, 2012), as can be seen in the following example.

The report also said that when two students had identical socioeconomic status and academic performance, a student who did not skip lessons in year 7 was on average three months ahead in their learning by year 9, compared with a student who had poor attendance.

In addition, the hard news story is considered to have an associating dialogic position with the attributed propositions. This can be seen when the 'validity' or 'truth' of the proposition is taken for granted - given. The associating dialogic position can usually be realised through several types of verbal processes, such as to demonstrate, to show, and to prove (White, 2008, 2012). The example of associating dialogic position is provided in the excerpt below.
Students who felt their teachers had high expectations of them did better in NAPLAN and were at least three months ahead of their peers by year 9 , according to a new report that shows a teacher's encouragement to work hard drives academic performance.

As far as types of evaluation in the hard news story are concerned, judgments and appreciations are dominant in the text. Judgments deal with evaluating students' performance and behaviour at school, while appreciations are geared towards the factors that may contribute to the improvement of students' NAPLAN outcome.

The report also said that when two students had identical socioeconomic status and academic performance, a student who did not skip lessons in year 7 was on average three months ahead in their learning by year 9 [+ve judgement], compared with a student who had poor attendance.

Positive [+ve appreciation] behaviour, which included not breaking school rules or being disruptive in class, also had a significant [+ve appreciation] impact on NAPLAN results and learning, the report says.

It must be noted that when delivering the evaluations towards students' performances and the contributing factors that may improve NAPLAN outcome, the hard news story attributes the source of information to the report. By providing such a strategy, the hard news story seems to position readers dynamically to align with the value positions that the text intends to share, i.e. communing around possible solutions to lift NAPLAN outcome. Such evaluations are potentially useful to prime and condition readers to respond to implicit evaluations (Coffin \& O'Halloran, 2006) through attribution found in the text (for further details regarding readers positioning, see Coffin \& O’Halloran, 2005; White, 2008).

\section{Evaluations in comment piece}

This section shifts gears into the discussion of evaluative resources in the comment piece. Different from the hard news story, the evaluation patterns found in the comment piece tend to be direct in that attributions of information do not seem to be the focus in this kind of text. The author becomes the sole appraiser in the text. This choice of evaluative strategy leads to the 'subjective' and personal voice of the text as the evaluations are primarily geared towards what the author and other people think or believe regarding NAPLAN test.

In terms of authorial voice, the comment piece resembles a commentator voice in that personal thoughts, judgements, affect, and appreciation are foregrounded in the text. It can be seen when the author scaffolds the development of her position and arguments. Stories concerning her own and others' experiences relating to NAPLAN test are foregrounded to emphasise the points. This story also plays as a 'contextual metaphor' (Martin \& Rose, 2008) in which arguments concerning NAPLAN test are packed into a 
form of story. Before asserting her position, she recounts her experiences on interviewing top leaders, politicians and scientists, judging them positively through their achievements.

In more than 25 years' of journalism, I've never interviewed a leader who topped [+ve judgment] his or her class at school.

Not a business leader like the steel-minded Gail Kelly or international scientist Professor Ian Frazer, whose science helped deliver the cervical cancer vaccine. [ $t$; +ve judgement]

Not church leaders or politicians, merchant bankers. Not even Queensland's chief entrepreneur Mark Sowerby. [t; +ve judgment]

So why do we continue to push along - and judge our teachers - on the success or otherwise of a NAPLAN test? [t; -ve appreciation]

This serves as the backbone information relating to the position challenged in the text. In stating her position, she raises another question loaded by evaluations directed towards readers and herself (we): So why do we continue to push along [-ve judgment: veracity]-and judge [-ve judgement: veracity] our teachers - on the success or otherwise of a NAPLAN test? By doing this, she construes her subjective assessment regarding the view on blaming teachers, putting we as the responsible doer regarding the act of blaming. This subjective assessment on people as well as on the view on blaming teachers is not mediated through attribution. It thus indicates that the author legitimates herself as a sole appraiser on the issue (Don, 2011; White, 2012).

As far as patterns of evaluations are concerned, there are several instances of attribution that can be observed in the text. Compared to the function of attribution found in the hard news story, the attributions in the comment piece serve different purposes. Rather than providing a seemingly 'objective' or neutral information, attributions in the comment piece are geared towards invoking a sense of evaluative meaning regarding the proposition that is shared (Feez et al., 2008). The following instance concerns the attribution used in the comment piece.

She tried teaching first, and it didn't work out. Her grades were good, not great. She says leadership is as much about what you don't know as you do.

This impersonalised attribution carries positive evaluation on leadership, legitimising Ms. Kelly as the person responsible for such an evaluation. In this particular case, there is an indication that the author intends to deliver a seemingly objective information by reporting what other people say regarding leadership, thus potentially backgrounding her subjective assessment of leadership (Bednarek \& Caple, 2017).

In addition, the author of the comment piece deploys instances of nominalised attributions. Insofar as results of analysis are concerned, examples of nominalisation can be seen when the author tries to background her role as an Agent when arguing for the points as in Now that's not an argument against testing, and turning qualities into nominalised elements, such as an inner resilience and an ability to lead others, and the dangers of social media to yoga. In this particular case, nominalisation is used primarily to reconfigure representation of realities, thus enabling writers to make generalisations regarding social activities, relations, and qualities, as well as coupling its meanings with the evaluations they intend to share. As a result, the text can be said to position readers to align with the value position as well as negotiating solidarity that NAPLAN is not a single, objective measurement in deciding future success.

\section{Interpersonal meanings in photojournalism}

After exploring evaluative resources in the hard news story and the comment piece, this section discusses interpersonal meanings realised through imagic resources in photojournalism (see Figure 3). Interpersonally, the image accompanying the hard news story offers viewers to observe a represented event and to align it to their feelings and social worlds. The way the image does this can be argued in two ways.

Firstly, from the orientational perspective, the image positions viewers in a way that the represented event is immediate to their social worlds, indicated by the use of long-shot. Regarding power relations, the image puts the viewers in a slightly superior position to the image. This suggests that viewers tend to have more power than the represented participant and event in the image (Kress \& van Leeuwen, 2006; van Leeuwen, 2004). In terms of affect, the image offers viewers to observe what is going on as there is no indication of eye-contact: the represented participant is looking down at the test sheet. However, as there is no instance of facial emotions depicted, the affectual sources are construed by other interpersonal sources in the image such as ambience.

Secondly, from the perspective of ambience, the choice of colours also contributes to the enactment of interpersonal meanings in the image. As far as results of ambience analysis suggest, the vibrancy tends to be soft, indicated by the median saturation or dim in most parts of the image. The choice of this saturation indicates that the image tries to tune down viewers' emotional response (Kress \& van Leeuwen, 2002). In terms of warmth, the image mostly uses warm colour, e.g. orange and brownish, foregrounding values that are possibly associated with the circumstance of place in which the 'doing a test' takes place. Complementing warmth, a slight colour differentiation can be observed, signalling that the image construes the 'doing a test' as a familiar social event (Kress \& van Leeuwen, 2002, 2006), thus inviting viewers to align themselves with the feelings invoked by the image. In this case, the invocation of emotional reactions is achieved subtly through the choice of colours and vibrancy surrounding the represented action - enveloped. 


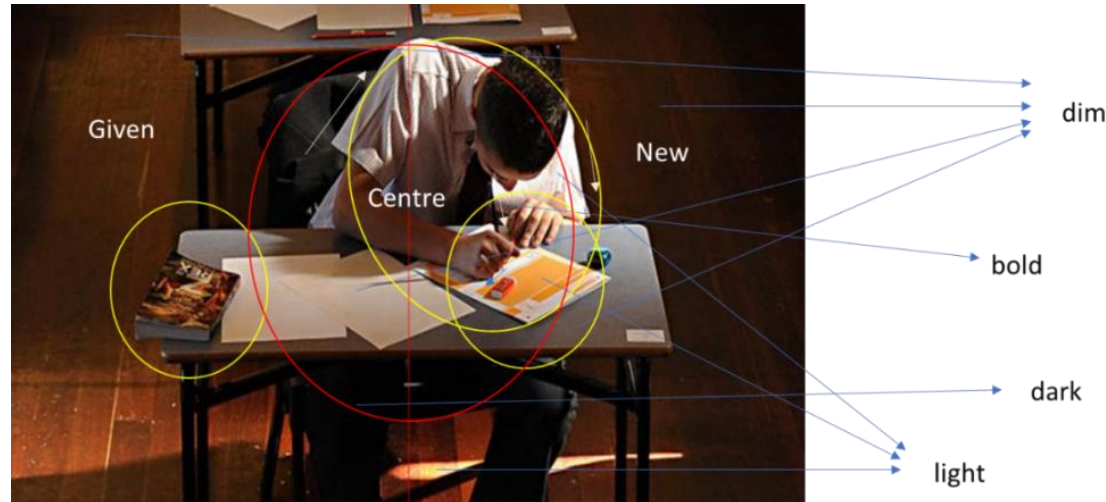

Figure 3 An analysis of photojournalism accompanying the hard news story

\section{Interpersonal meanings in political cartoon}

The cartoon interpersonally invites viewers to observe and negotiate the feelings regarding the anxiety of facing NAPLAN test (see Figure 4). Orientational and ambience elements capture the way image positions and aligns viewers with the feelings shared in the image.

From orientation perspective, the cartoon does not invite a direct engagement from the viewers. Rather, it affords them to observe what is going on. The interactive event is captured in a relatively long shot, suggesting that it is something that invites public attention. It is also strengthened by the way power relations are observed in the cartoon. The image aligns solidarity in terms of power relations with the viewers. This suggests that both viewers and the interactive participants share an equal position in power (Kress \& van Leeuwen, 2006). However, insofar as the construal of the event as a public affair is concerned, the viewers seem not to have any direct involvement with what is going on in the image. The oblique angle indicates that the viewers are in a disjunction with the interactive participants. The viewers are, indeed, aligned with the NAPLAN test paper, as it is placed in a direct, frontal angle with the viewers. This suggests that, rather than aligning the viewers with interactive participants, the image positions NAPLAN test as something which immediately relates to their social worlds.

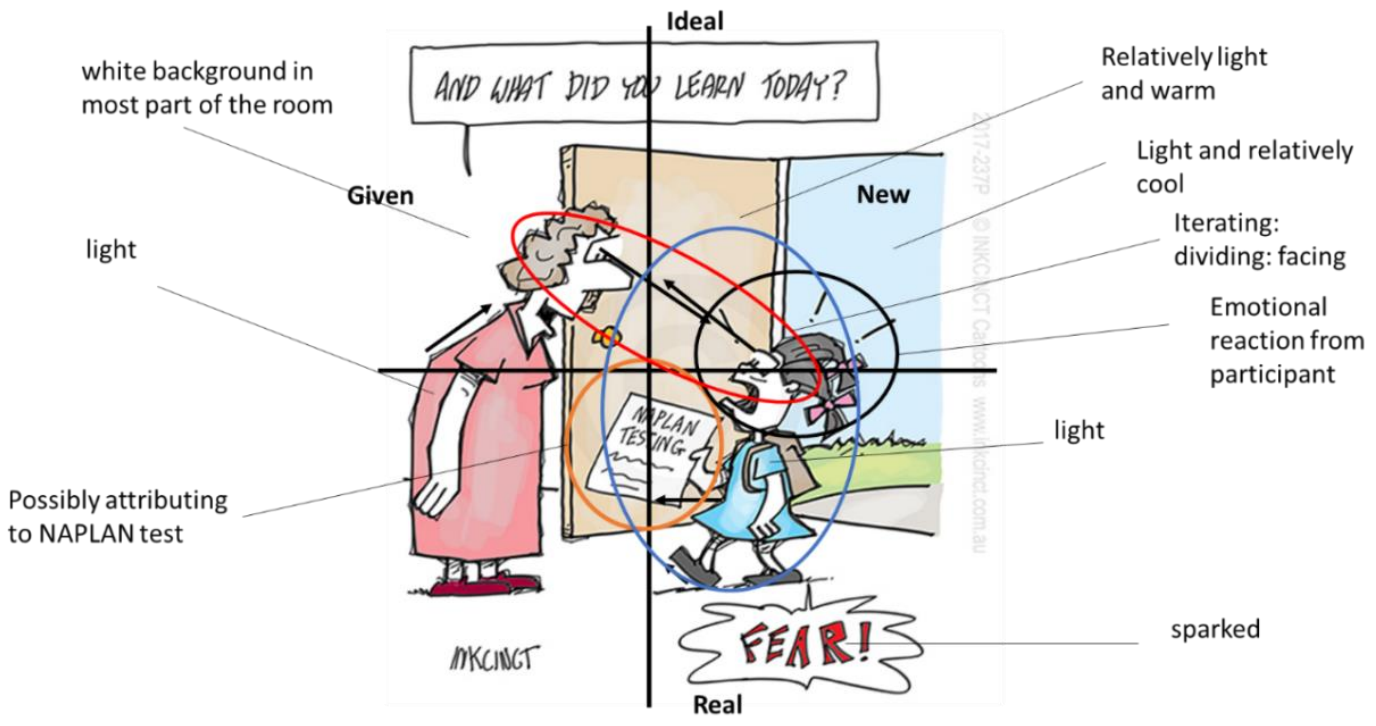

Figure 4 An analysis of a political cartoon relating to NAPLAN test

In addition to positioning viewers through the aspects aforementioned, affectual sources are used to construe the fear of facing NAPLAN test. These sources are primarily indicated in the child's facial expression and exclamation marks, signalling unhappiness and insecurity caused by NAPLAN test. These feelings become real as the image puts the FEAR boldly in the 'real' domain. Construing a fearful impact of having NAPLAN test in this way, the image can function to provide evaluations by means of sharing negative attitude (Swain, 2012) towards the impact of NAPLAN test, thus indicating that this issue needs to be taken care of seriously.

The use of colours in the cartoon also contributes to the creation of interpersonal nuances in the image. Two contrastive aspects of colour can be observed in the cartoon. Firstly, a monochromatic saturation is used to give a relatively removed feeling attributed to the room - distancing viewers with the feeling colouring the house (Kress \& van Leeuwen, 2002). Secondly, 'the 
outside' world is depicted as being more colourful and cooler than the house. Apart from distancing viewers with feelings inside the house, the cartoon at the same time directs viewers' attention to the 'real' world in which many activities, including NAPLAN test, take place. Having said this, the outside world is construed as having a higher degree of familiarity to the viewer's social worlds.

In addition to the use of contrastive colour saturation, the interpersonal nuances of the cartoon are hugely influenced by the use of word FEAR sparked in a speech bubble. The colour of FEAR is very bold (red), and it flashes out of the monochromatic colour of the house. This element functions as an associative value (Kress \& van Leeuwen, 2002) indicating the overall evaluations towards the issue (NAPLAN test) as well as symbolising dominant feeling surrounding the issue that the cartoon maker intends to share.

\section{Text-image relations}

After discussing the organisation of interpersonal meanings in the hard news story, comment piece, photojournalism, and cartoon, this paper is now in a position to elaborate the relation between texts and images with regard to the multimodal construal of NAPLAN test in the media. As has been elaborated previously, the hard news story and photojournalism complementarily establish an expository relation (Martinec \& Salway, 2005) in which both text and image develop a set of complex, interrelated meanings regarding the influence of positive engagement to the outcome of NAPLAN test. In doing so, intersemiotic relations (Liu \& O’Halloran, 2009; O’Halloran, 2008) between meanings in the news story and the image are maintained by both specific referential items and positionality of NAPLAN test sheet in the image NAPLAN test is construed as a non-agreed upon element indicated by its position in New cline of the image. Additionally, the feelings construed in the image are largely invoked as the choice of colours signalling affectual resources is enveloped.

The comment piece and cartoon try to invite readers to share collective feelings regarding NAPLAN test. The comment piece is geared towards challenging a particular view regarding blaming teachers for the success or failure of NAPLAN test. Throughout the text, contrastive evaluations between the education system and notable people who seemingly did not ace NAPLAN test are foregrounded. The author organises the text in a personal manner in that the evaluations of people, NAPLAN, and education system are revolving around the author's and other people's experiences. Similarly, the image also utilises several evaluative resources to align viewers with the feelings they intend to share (Caple, 2013; Swain, 2012). From orientational and ambience perspective, the feeling of FEAR is the most salient element in the image. It is also strengthened by its presentation as a real element. The colour used is very bold, indicating that the fear caused by NAPLAN test is obviously real. In addition, NAPLAN test is construed as the most central element in the image, indicating that viewers should pay close attention to it. Such an organisation necessitates viewers to infer (Martinec, 2013) potential complementarity between both linguistic and imagic elements used to construe NAPLAN test.

Putting all these resources together, it can be said that both texts and images orient readers to align with shared evaluations regarding the construal of the controversial NAPLAN in the Australian context.

\section{CONCLUSION}

This paper has elaborated in some detail how interpersonal meanings in texts and images contribute to the construal of the problematic NAPLAN test in one leading Australian online newspaper. Utilising SFLinformed discourse analysis toolkits, this paper exemplifies how those resources capture media attempts on aligning audiences' feelings and negotiating solidarity regarding the problem of NAPLAN test. Both linguistic and imagic resources tend to position audiences to accept communal values regarding the construal of NAPLAN. Linguistic resources in the hard news story and the comment piece position readers dynamically to align with the value positions that the text intends to share. The hard news story deploys a seemingly 'objective' stance with regard to the potential factors that contribute to the improvement of NAPLAN outcome. Meanwhile, the comment piece personalises the evaluations in order that readers can position themselves to align with the value position as well as negotiating solidarity that NAPLAN is not a single, objective measurement in deciding future success.

Some further improvement extending the appliability of the analyses provided in this paper can be suggested. As this paper focuses on exemplifying the appliability of Appraisal and imagic analyses in a small corpus of media texts, future investigations are recommended to include a larger example of data in order to see how this framework can flesh out the realisation of interpersonal meanings in media discourse in a more delicate manner. In addition, this framework can also be used with other approaches of discourse analysis such as Critical Discourse Analysis (CDA) or Positive Discourse Analysis (PDA) with the focus of making explicit how objectivity of information/facts is achieved in media texts. Lastly, future investigations are also recommended to pay closer attention to the indirect realisations of attitude (invoked attitudes) by complementing Appraisal analysis with Legitimation Code Theory (LCT) in order to provide a more delicate account on seeing how texts position readers in relation to the community discourse practices.

\section{Texts analysed}

Inkcinct. (2017). What did you learn today. Retrieved November 8, 2017, from https://www.inkcinct.com.au/webpages/cartoons/past/2017/2017-237P--What-did- 
you-learn-today,-NAPLAN-testing--EDUCATION-AUSTRALIA--INKCINCT.jpg

King, M. (2017). How many of our bosses would have aced NAPLAN tests? Retrieved September 12, 2017, from http://www.smh.com.au/comment/thatthinking-feeling/how-many-of-our-bosses-wouldhave-aced-naplan-tests-20170802-gxo72j.html

Smith, A. (2017, September 4). High expectations, attendance key to lifting NAPLAN score: report. Retrieved September 15, 2017, from http://www.smh.com.au/national/education/highexpectations-attendance-key-to-lifting-naplanscores-report-20170904-gyadr3.html

\section{REFERENCES}

ACARA. (2017). National assessment program: Literacy and numeracy. Sydney.

Angelo, D. (2013). NAPLAN implementation: Implications for classroom learning and teaching, with recommendations for improvement. TESOL in Context, 23(1 \& 2), 53-73.

Bednarek, M., \& Caple, H. (2017). The discourse of news value: How organisations create newsworthiness. New York: Oxford University Press.

Caple, H. (2013). Photojournalism: A social semiotic approach. Houndsmills: Palgrave Macmillan.

Coffin, C., \& O'Halloran, K. L. (2005). Finding the global groove: Theorising and analysing dynamic reader positioning using APPRAISAL. Critical Discourse Studies, 2(2), 143-163. https://doi.org/10.1080/17405900500283607

Coffin, C., \& O'Halloran, K. L. (2006). The role of appraisal and corpora in detecting covert evaluation. Functions of Language, 13(1), 77-110. https://doi.org/10.1075/fol.13.1.04cof

Cumming, J. J., Wyatt-Smith, C., \& Colbert, P. (2016). Students at risk and NAPLAN: The collateral damage. In B. Lingard, G. Thompson, \& S. Sellar (Eds.), National testing in schools: An Australian assessment (pp. 126-138). Abingdon, Oxon: Routledge.

Don, A. C. (2011). Legitimating tenor relationships: Affiliation and alignment in written interaction. Linguistics and Education, 5(3), 303-327. https://doi.org/10.1558/lhs.v5i3.303

Eggins, S. (2004). Introduction to systemic functional linguistics (2nd ed.). London: Continuum.

Eggins, S., \& Slade, D. (1997). Analysing casual conversation. London: Cassel.

Feez, S., Iedema, R., \& White, P. R. R. (2008). Media literacy. Sydney: NSW AMES.

Halliday, M. A. K. (1978). Language as a social semiotic: The social interpretation of language and meaning. Baltimore: University Park Press.

Halliday, M. A. K., \& Matthiessen, C. M. I. M. (1999). Construing experience through meaning : A language-based approach to cognition. London: Continuum.
Halliday, M. A. K., \& Matthiessen, C. M. I. M. (2014). Halliday's introduction to functional grammar (4th ed.). Oxon: Routledge.

Hjelmslev, L. (1961). Prolegomena to a theory of language. Madison: The Universty of Wsiconsin Press.

Johnston, J. (2017). Australian NAPLAN testing: In what ways is this a 'wicked' problem? Improving Schools, 20(1), 18-34. https://doi.org/10.1177/1365480216673170

Kress, G., \& van Leeuwen, T. (2002). Colour as a semiotic mode: Notes for a grammar of colour. Visual Communication, 1(3), 343-368. https://doi.org/10.1177/147035720200100306

Kress, G., \& van Leeuwen, T. (2006). Reading images: The grammar of visual design (2nd ed.). Abingdon: Routledge.

Lingard, B., Thompson, G., \& Sellar, S. (2016). National testing from an Australian perspective. In B. Lingard, G. Thompson, \& S. Sellar (Eds.), National testing in schools: An Australian assessment (pp. 1-17). Abingdon, Oxon: Routledge.

Liu, Y., \& O’Halloran, K. L. (2009). Intersemiotic texture: Analyzing cohesive devices between language and images. Social Semiotics, 19(4), 367-388. https://doi.org/10.1080/10350330903361059

Martin, J. R. (1992). English text: System and structure. Amsterdam: John Benjamins.

Martin, J. R. (2013). Systemic functional grammar: A next step into theory---axial relations. Beijing: Higher Education Press.

Martin, J. R., Quiroz, B. E., \& Wang, P. (in preparation). Systemic functional grammar: Another step into theory - grammatical description. Beijing: Higher Education Press.

Martin, J. R., \& Rose, D. (2007). Working with discourse: Meaning beyond the clause (2nd ed.). London: Continuum.

Martin, J. R., \& Rose, D. (2008). Genre relations: Mapping culture. London: Equinox.

Martin, J. R., \& White, P. R. R. (2005). The language of evaluation: Appraisal in English. Houndsmills: Palgrave Macmillan. https://doi.org/10.1057/9780230511910

Martinec, R. (2013). Nascent and mature uses of a semiotic system: The case of image-text relations. Visual Communication, 12(2), 147-172. https://doi.org/10.1177/1470357212471603

Martinec, R., \& Salway, A. (2005). A system for imagetext relations in new (and old) media. Visual Communication, 4(3), 337-371. https://doi.org/10.1177/1470357205055928

Matthiessen, C. M. I. M., \& Halliday, M. A. K. (2009). Systemic functional grammar: A first step into the theory. Beijing: Higher Education Press.

Mockler, N. (2013). Reporting the 'Education Revolution': MySchool.edu.au in the print media. Discourse: Studies in the Cultural Politics of 
Education, 34(1), 1-12. https://doi.org/10.1080/ 01596306.2012 .698860

Mockler, N. (2016). NAPLAN and the problem frame: Exploring representations of NAPLAN in the print media, 2010 and 2013. In B. Lingard, G. Thompson, \& S. Sellar (Eds.), National Testing in Schools: An Australian assessment (pp. 181-198). Abingdon, Oxon: Routledge.

O’Halloran, K. L. (2008). Systemic functionalmultimodal discourse analysis (SF-MDA): Constructing ideational meaning using language and visual imagery. Visual Communication, 7(4), 443-475. https://doi.org/10.1177/1470357208096210

Swain, E. (2012). Analysing evaluation in political cartoons. Discourse, Context and Media, 1(2-3), 82-94. https://doi.org/10.1016/j.dcm.2012.09.002

Thompson, G., \& Harbaugh, A. G. (2013). A preliminary analysis of teacher perceptions of the effects of NAPLAN on pedagogy and curriculum. Australian Educational Researcher, 40(3), 299314. https://doi.org/10.1007/s13384-013-0093-0 van Leeuwen, T. (2004). Introducing social semiotics. Abingdon: Routledge.
White, P. R. R. (2004). Subjectivity, evaluation and point of view in media discourse. In C. Coffin, A. Hewings, \& K. L. O’Halloran (Eds.), Applying English grammar: Functional and corpus approaches (pp. 230-246). London: The Open University Press.

White, P. R. R. (2008). Praising and blaming, applauding, and disparaging - solidarity, audience positioning, and the linguistics of evaluative disposition. In G. Antos, E. Ventola, \& T. Weber (Eds.), Handbook of interpersonal communication (pp. 567-594). Berlin: Walter de Gruyter.

White, P. R. R. (2012). Exploring the axiological workings of "reporter voice" news storiesattribution and attitudinal positioning. Discourse, Context and Media, 1(2-3), 57-67. https://doi.org/10.1016/j.dcm.2012.10.004

Wigglesworth, G., Simpson, J., \& Loakes, D. (2011). Naplan language assessments for indigenous children in remote communities: Issues and problems. Australian Review of Applied Linguistics, 34(3), 320-343. https://doi.org/10.1075/aral.34.3.04wig 